\title{
CRIMINAL LEGAL CHALLENGES TO THE UPTAKE OF EFFECTIVE HIV TRANSMISSION PREVENTION TECHNOLOGIES AND THE ROLE OF MEDICAL ADVICE
}

\author{
DAVID J. CARTER
}

\section{THIS ARTICLE IS A PREPRINT AND HAS NOT BEEN PEER-REVIEWED.}

$\underline{\text { Introductory Line }}$

Public health and biosecurity law puts at risk the sustainability of PrEP and $\mathrm{U}=\mathrm{U}$ in Australia.

\section{$\underline{\text { Abstract }}$}

Treatment-as-prevention ('TasP' or 'U=U') and pre-exposure prophylaxis ('PrEP') represent major advances in the prevention of HIV transmission. As time progresses, both interventions are having positive impacts on HIV transmission rates in Australia and are refashioning the meaning of 'safer sex' amongst priority populations.

Despite this success, there is a risk that the law will undermine the effectiveness of these important new interventions by failing to keep up with these advances. It is time to implement a 'medical advice' law that will ensure that public health law remains evidence-based while reinforcing the doctor-patient relationship.

\section{Introduction}

Two recent advances in the prevention of HIV transmission have radically changed the meaning of what constitutes 'safer sex': treatment-as-prevention ('TasP'), popularised through the campaign undetectable $=$ untransmissible (' $U=U$ '), and pre-exposure prophylaxis ('PrEP').

Growing policy and clinical acceptance of these biomedical prevention technologies has led to their widespread implementation amongst priority populations in Australia, resulting in promising reductions in HIV transmission rates.

Unfortunately, the long-standing tension between law and effective transmission reduction practices may well rear its head again, risking the sustainability and effectiveness of these new approaches. This article argues that recognising the role of 'medical advice' in public health law would help to close this gap between medical consensus, evidence-based practice and the law.

\section{PrEP and U=U: Effective HIV Transmission Prevention Interventions}

PrEP and TaSP/U=U are new approaches to the prevention of HIV transmission. ${ }^{1}$ PrEP is a preventive regimen of antiretroviral treatment ('ART') taken by those at risk of transmission, which is proven to prevent HIV transmission. ${ }^{2} \mathrm{TaSP} / \mathrm{U}=\mathrm{U}$ involves the application of the principle of 'treatment-as-prevention', where a person living with HIV uses ART to supress the virus to the point where it is said to be 'undetectable'. ${ }^{3}$ Recent guidance from the Australasian 
Society of HIV, Viral Hepatitis and Sexual Health Medicine concludes that maintaining a durable viral suppression in this way 'eliminates the risk of sexual HIV transmission'.

Whilst acceptance of PrEP and TasP by the medical community has led to widespread adoption of these prevention approaches amongst relevant populations, the law and the legal system has not yet engaged with these major advances. This leaves the law potentially 'out of step' with current medical advice and widespread practice.

\section{Australian Public Health Law Requires 'Reasonable Precautions' and 'All Reasonable Steps' Against Transmission}

Australian public health law imposes various duties upon those living with HIV and other relevant communicable diseases. This includes that they take practical steps to reduce the risk of transmission and thus risk to the public health. ${ }^{5}$ Whilst the details differ between each jurisdiction, there are two main approaches to the creation of this legal duty in Australia. The first requires those living with HIV or other relevant communicable conditions take all reasonable precautions or steps or exercise all due diligence to prevent transmission. ${ }^{6-11}$ The second approach creates a duty to simply take 'reasonable precautions' against transmission. ${ }^{12}$ Failure to discharge this duty can result in fines and imprisonment of between six months and ten years depending on the jurisdiction and seriousness of offence.

Given the very serious consequences that accompany a breach of these laws, what is required of a person should be made very clear. At present, however, this is not the case. Patients may rely on the advice of their medical practitioners, who provide education and support attuned to the patient and their particular condition. This is supported, in some jurisdictions, by a requirement that the newly diagnosed be provided with specific information and education regarding transmission reduction techniques by their medical practitioner. ${ }^{12}$ Some jurisdictions also provide formal public guidance on the topic. Western Australia, for example, specifies that the Department of Health in that state considers practices like the use of barrier precautions, a sexual partner taking PrEP, or maintaining an undetectable viral load constitute a reasonable precaution. ${ }^{12}$ This is the sort of clarity which those living with HIV or other relevant communicable conditions should be able to rely upon to support their compliance with law, especially when the consequences are so serious.

Unfortunately, whilst useful, none of these sources of guidance are recognised by law as authoritative. Instead, it is left up to courts to determine the meaning of what constitutes a 'reasonable step', 'reasonable precaution' or the 'exercise of due diligence'. This requires a case be brought, and until such time that it is, there is a lack of clarity regarding their meaning. This leaves those living with HIV or other relevant communicable conditions in a situation where they are required to take steps or precautions, which are not clearly defined until a court decides what their meaning is.

The failure to provide clear guidance is particularly acute regarding PrEP and TaSP/U=U. Both forms of prevention are highly effective. However, due to their relative novelty, the law has yet to confirm whether and when such prevention methods will be regarded as acceptable, and thus a defence to a breach of public health law in relevant jurisdictions. This leaves the status of these uniquely effective prevention methods in a legal 'grey zone'.

Waiting for a court to clarify the meaning of these terms is one approach to resolving this challenge. However, this creates other risks, as a court might impose a meaning that differs even widely - from current evidence or individualised medical advice relied upon by a patient from a practitioner who knows them best. The experience in Canada provides a warning in this regard, where the Supreme Court of Canada in $R v$ Mabior confirmed that only condom use 
combined with antiretroviral therapy reduces risk sufficiently to preclude liability for a HIVrelated offence in that jurisdiction. ${ }^{14}$ This decision has been critiqued on the basis that it fails to reflect current evidence, and differs dramatically from public health practice and messaging regarding transmission reduction. ${ }^{15}$ The result can only be an undermining of public health efforts, and the integrity of the doctor-patient relationship.

Given that the purpose of public health law is to manage and reduce risk to the public health, in this context its role is to support effective transmission reduction. Australian public health and biosecurity law fails to achieve this aim by failing to generate sufficiently clear signals to those living with HIV or other relevant communicable conditions. Given that PrEP and $\mathrm{TaSP} / \mathrm{U}=\mathrm{U}$ are so effective, we should be doing all we can to ensure no barrier standards in the way of their widespread use, nor of the ability for people living with HIV to comply with law.

\section{Recognising the Role of Medical Advice}

One solution to this challenge is to explicitly define what constitutes a reasonable precaution, step or due diligence in law. This would involve listing particular practices, like PrEP use or $\mathrm{U}=\mathrm{U}$ in statutory texts. This approach, however, creates further risks. Firstly, it risks creating unexpected outcomes by 'freezing' current medical practices and science into law. This makes it increasingly difficult for the law to reflect changing practices over time, whilst impeding the ability of medical science and professional bodies to adopt evidence-based practices as they emerge. Secondly, such an approach limits medical practice itself, limiting the ability of patients to adopt prevention practices that suit their particular circumstances where they fall outside of strict or poorly drafted legal definitions. For these reasons, this approach is not regarded as a good approach to law making in this field, or any other.

A better approach to this challenge is to introduce a provision that recognises and supports patients to follow 'medical advice'. This is achieved by modifying public health law to the effect that a person will fulfil their duty, or be safe from prosecution, where they take precautions on the basis of medical advice. Reform to the definition of offences or the available of defences could, for example, simply state that 'a reasonable precaution includes precautions taken on the advice of a medical practitioner.'

The Australian Capital Territory already utilises this approach, noting in their definition of reasonable precaution that this 'includes precautions taken on the advice of a doctor' ${ }^{10}$ Other jurisdictions come close to this proposal, with South Australia and Western Australia, for example, advising a person will not be in breach of their general public health duty to prevent or minimise harm to the public health where they act 'in a manner or in circumstances that accord with generally accepted practices' ${ }^{8,9}$ However, this form of words fails to specify medical advice as a source of 'generally accepted practices'. Nor does it operate as a defence to the criminal offences created by public health law in those jurisdictions. For this reason, it too should be reformed.

The advantage of the medical advice approach is that it would not limit or 'freeze' the meaning of reasonable precaution, step or due diligence. Instead, it would allow the definition to change freely over time in response to emerging evidence, clinical practice and, finally, to a person's own particular circumstances. This would include medical advice received either from the patient's own doctor or, indeed, by an appropriate public health official.

\section{A Focus on Evidence and Clinical Care for Patients}

What, implications might this reform create for medical practitioners and clinical practice? The answer is, very few. Indeed, there are significant advantages to practitioners and their practice 
should this reform be enacted. Medical practitioners already provide information or education to the newly diagnosed regarding transmission reduction strategies. This reform would simply give further support to those efforts, with patients 'incentivised' to engage and enact the advice received by their treating practitioner. Moreover, the reform creates no additional duty for health practitioners, and creates no liability for them should a patient fail to successfully follow advice and education. Instead, this reform would simply align the law and its requirements with current clinical practice. It would reduce the risk of law imposing a definition at odds with evidence-based approaches. It would further advance the aims of public health by providing less ambiguous guidance to patients on how to fulfil their legal duty in a way that is attuned to the patient's own circumstances, condition and established within the context of their existing clinical relationships. 
1. Boyd M, Cooper D, Crock EA, Crooks L, Giles ML, Grulich A, et al. Sexual transmission of HIV and the law: an Australian medical consensus statement. Med J Aust. 2016;205:409-12.

2. Okwundu CI, Uthman OA, Okoromah CA. Antiretroviral pre-exposure prophylaxis (PrEP) for preventing HIV in high-risk individuals. In: The Cochrane Library [Internet]. John Wiley \& Sons, Ltd; 2012 [cited 2018 Apr 16]. Available from: http://cochranelibrary-wiley.com/doi/10.1002/14651858.CD007189.pub3/full

3. Prevention Access Campaign. Risk of Sexual Transmission of HIV from a Person Living with HIV Who Has an Undetectable Viral Load ('U=U Consensus Statement') [Internet]. Prevention Access Campaign; 2016 [cited 2017 Sep 20]. Available from: https://www.preventionaccess.org

4. The Australasian Society of HIV, Viral Hepatitis and Sexual Health Medicine. $\mathrm{U}=\mathrm{U}$ ASHM Guidance for Healthcare Professionals. Allen B, editor. Australasian Society for HIV, Viral Hepatitis and Sexual Health Medicine (ASHM); 2020.

5. Carter DJ. Transmission of HIV and the Criminal Law: Examining the impact of pre-exposure prophylaxis and treatment-as- prevention. Melb Univ Law Rev. 2019;43:937-86.

6. Public Health and Wellbeing Act 2008 (VIC), s 111(b)-(c)(ii)

7. Public Health Act 2005 (QLD) s 66(1b) placing the onus on the person at risk of contracting a communicable disease.

8. Public Health Act 2016 (WA) ss 39, 88(4), 88(2)

9. South Australian Public Health Act 2011 (SA), ss 56, 56(3)(a), 59

10. Public Health Act 1997 (Tas), s 51

11. Public Health Regulations 2000 (ACT), reg. 21

12. Public Health Act 2010 (NSW), s 79

13. Communicable Disease Control Directorate, Department of Health, Government of Western Australia. Fact Sheet Public Health Act 2016 (WA): Part 9 Notifiable Infectious Diseases and Related Conditions (Understanding 'Reasonable Precautions') [Internet]. Department of Health, Government of Western Australia; 2019 [cited 2021 May 10]. Available from: https://ww2.health.wa.gov.au//media/Files/Corporate/general-documents/Sexual-Health/PDF/Notifiable-infectiousdiseases-fact-sheet.pdf

14. R. v Mabior (2012) SCC 47

15. Grant I. The Over-Criminalization of Persons with HIV. Univ Tor Law J. 2013;63:475-84. 

HEADER (IF REQUIRED) 